\title{
Outer-Sphere Tyrosine 159 within the 3-Mercaptopropionic Acid 2 Dioxygenase S-H-Y Motif Gates Substrate-Coordination Denticity at 3 the Non-Heme Iron Active Site
}

Sinjinee Sardar ${ }^{1}$, Andrew Weitz ${ }^{2}$, Michael P. Hendrich ${ }^{2}$, Brad S. Pierce ${ }^{3 *}$

${ }^{1}$ Department of Chemistry and Biochemistry, The University of Texas at Arlington, 700 Planetarium Place, Arlington, TX 76019

${ }^{2}$ Department of Chemistry, Carnegie Mellon University, 4400 Fifth Avenue, Pittsburgh, PA 15213

${ }^{3}$ Department of Chemistry and Biochemistry, University of Alabama, 250 Hackberry Lane, Tuscaloosa, AL 35487

Table S1. Sequence of primers used in QuikChange Lightning site directed mutagenesis kit.

\begin{tabular}{lll} 
Primer & Sequence & $T_{m}\left({ }^{\circ} \mathrm{C}\right)$ \\
\hline Y159F forward & AGCATCCATGTCTTTGGCGCCAACATCGGTGCC & 69.3 \\
Y159F reverse & GATGTTGGCGCCAAAGACATGGATGCTGATCGA & 66.1 \\
H157N forward & ATCAGCATCAATGTCTATGGCGCCAACATC & 62.3 \\
H157N reverse & GCCATAGACATTGATGCTGATCGACGGCTG & 63.8 \\
\hline
\end{tabular}

Oxygen saturation and coupling efficiency of wild-type and variant $A v$ MDO.

As previously reported, the wild-type enzyme exhibits no significant change in the initial rate at oxygen concentrations between $25-500 \mu \mathrm{M}$ regardless of $\mathrm{pH}^{1-2}$ This demonstrates that the apparent $K_{M}^{O 2}$ is significantly lower ( 10x) than the lowest value of oxygen utilized in these experiments and therefore binding of $\mathrm{O}_{2}$ to the substrate-bound enzyme complex can be treated as an irreversible process. ${ }^{3-4}$ Similarly, the $\mathrm{O}_{2}$-saturation behavior was measured for both $\mathrm{H} 157 \mathrm{~N}$ and Y159F variants of $A v$ MDO. Atmospheric oxygen concentration at 1 atm and ambient temperature $\left(37^{\circ} \mathrm{C}\right)$ is $\sim 220 \mu \mathrm{M}$. The initial rate of enzymatic reactions was measured at fixed, and saturating substrate concentrations [ 3 mpa $(300 \mu \mathrm{M})$ ], while varying $\mathrm{O}_{2}$ concentration by serial dilution of an $\mathrm{O}_{2}$-saturated buffer. Final dissolved oxygen concentration present in solutions was verified by oxygen electrode. All experiments were initiated by injection of enzyme $(1 \mu \mathrm{M})$ at three $\mathrm{pH}$-values spanning the functional range of the enzyme $(6.5,7.5$ and 9.5) to observe $\mathrm{pH}$ dependent perturbations (if any) in $\mathrm{O}_{2}$-saturation behavior. As illustrated in Supporting Information, Figure S1, the specific activity of these variants is largely independent of oxygen concentration down to $\sim 10 \mu \mathrm{M}$. Only in assays approaching stoichiometric oxygen relative to enzyme $(5 \pm 2 \mu \mathrm{M})$ is a significant decrease in the initial rate observed. Qualitatively, H157N and Y159F variants appear to have slightly higher apparent $K_{M}^{O 2}$-values relative the wild-type enzyme. However, these differences are within the experimental error of measurement $( \pm 7 \mu \mathrm{M})$; and thus, more sensitive measurements are needed to verify this observation. Regardless, it can be concluded that the kinetics for both variants are fully saturated in oxygen concentration under steady-state conditions using air-saturated buffer. 
Figure S1. Oxygen saturation of H157N and Y159F Av MDO variants.
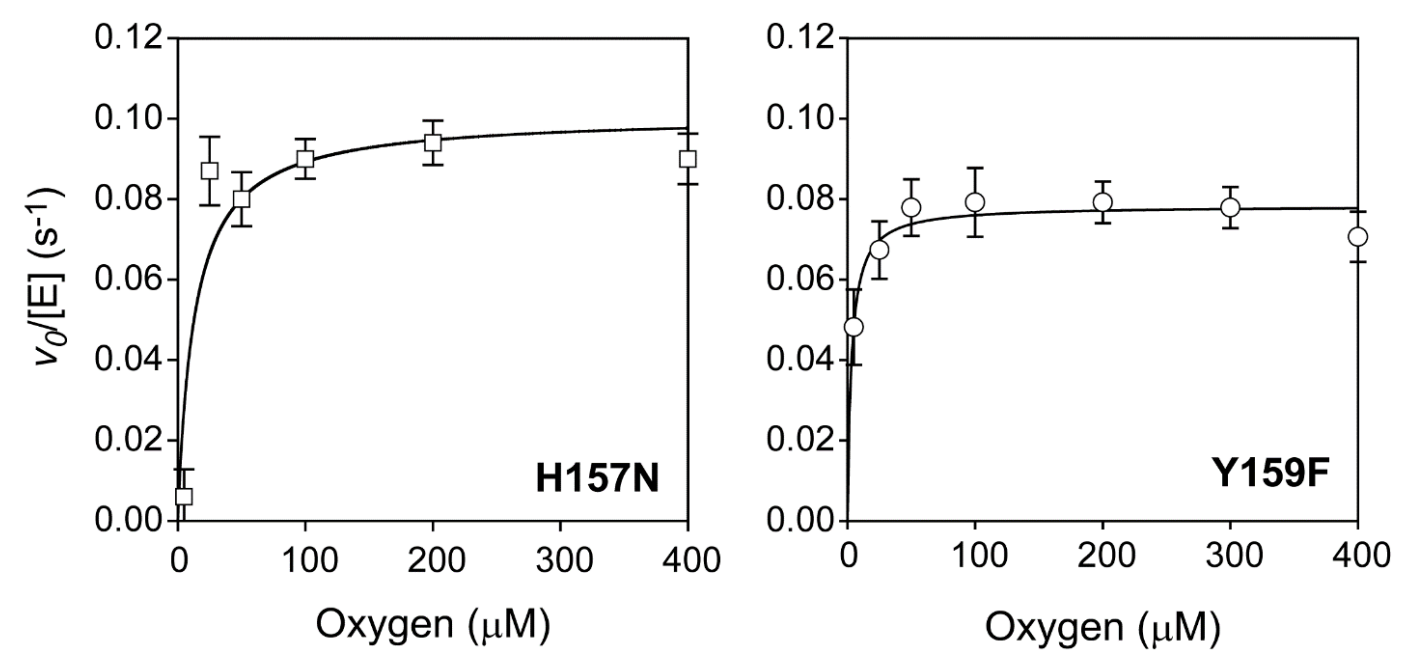

Figure S1. Steady-state oxygen saturation kinetics of $A v$ MDO variants H157N (left) and Y159F (right) at $37^{\circ} \mathrm{C}$ and $\mathrm{pH}$ 8.0. The solid lines represent best-fit Michaelis-Menten curves for each variant; $\mathrm{H} 157 \mathrm{~N}\left(k_{\text {cat }}, 0.10 \pm 0.01 \mathrm{~s}^{-1} ; K_{M}^{O 2}, 10 \pm 6 \mu \mathrm{M}\right)$ and $\mathrm{Y} 159 \mathrm{~F}\left(k_{\text {cat }}, 0.08 \pm 0.002 \mathrm{~s}^{-1} ; K_{M}^{O 2}, 3 \pm\right.$ $7 \mu \mathrm{M})$. Measurement of kinetics at oxygen concentrations below the apparent $K_{M}^{O 2}$ were experimentally feasible, so these values represent an upper limit. However, these results clearly demonstrate that $A v$ MDO kinetics is fully saturated in oxygen concentration.

Outer Fe-coordination sphere perturbations have a profound influence on the efficiency at which cysteine dioxygenase incorporates $1 \mathrm{~mol}$ of $\mathrm{O}_{2}$ into the final 3spa-product. This 'coupling' efficiency can be determined by taking the ratio of $k_{c a t}$-values obtained from $\mathrm{O}_{2}$-consumption measured polarographically by the rate of $\boldsymbol{c s} \boldsymbol{a}$-formation determined by HPLC. ${ }^{1,3,5-6}$ To minimize sample-to-sample variability and match reaction conditions in coupling experiments, aliquots for HPLC analysis are taken directly from the jacketed $2.5 \mathrm{~mL}$ oxygen electrode stir cell at selected time points, and reactions were quenched by spin-filtration $(0.22 \mu \mathrm{m})$ with a cellulose acetate membrane (Corning, Spin-X) prior to analysis. As previously reported ${ }^{6}$, nearly stoichiometric coupling was observed for the wild-type enzyme over the entire $\mathrm{pH}$ range assayed (Supporting Information, Figure S2). However, relative to the wild-type enzyme, both H157N and Y159F 3mpa assays exhibit significantly depleted coupling efficiencies with marked $\mathrm{pH}$-dependence. This uncoupling of variant $A v$ MDO catalysis is fairly consistent with what has been observed previously for C93A and H155A variants of the mammalian $\mathrm{Mm} \mathrm{CDO}{ }^{7}$ 
Figure S2. $\mathrm{pH}$-dependent $\left(\mathrm{O}_{2} / 3\right.$ spa)-coupling efficiency for $\mathrm{H} 157 \mathrm{~N}$ and $\mathrm{Y} 159 \mathrm{~F}$ variants as compared to wild-type Av MDO.

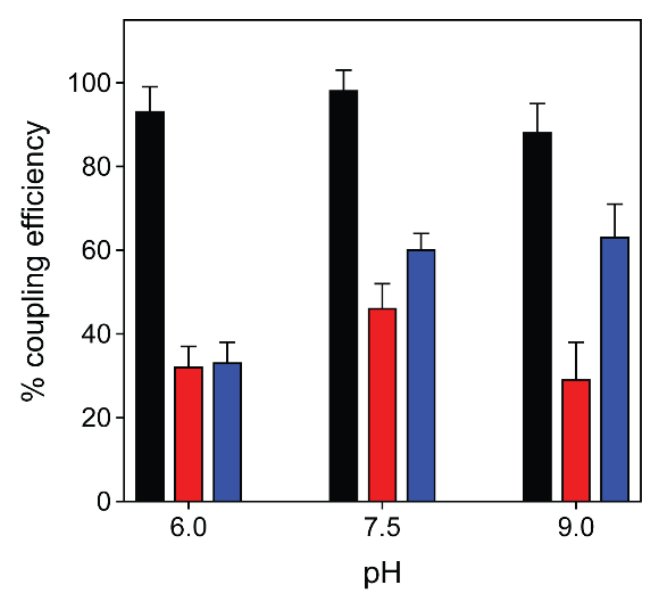

Figure S2. Influence of $\mathrm{pH}$ on $\left(\mathrm{O}_{2} / 3\right.$ spa $)$-coupling efficiency for the wild-type $A v \mathrm{MDO}$ (black) as compared to $\mathrm{H} 157 \mathrm{~N}$ (red) and $\mathrm{Y} 159 \mathrm{~F}$ (blue) variants.

\section{Dixon-Webb analysis of Y159F Av MDO pH-dependent substrate inhibition.}

Figure S3. $p H$ dependent substrate inhibition observed for the Y159F Av MDO variant.
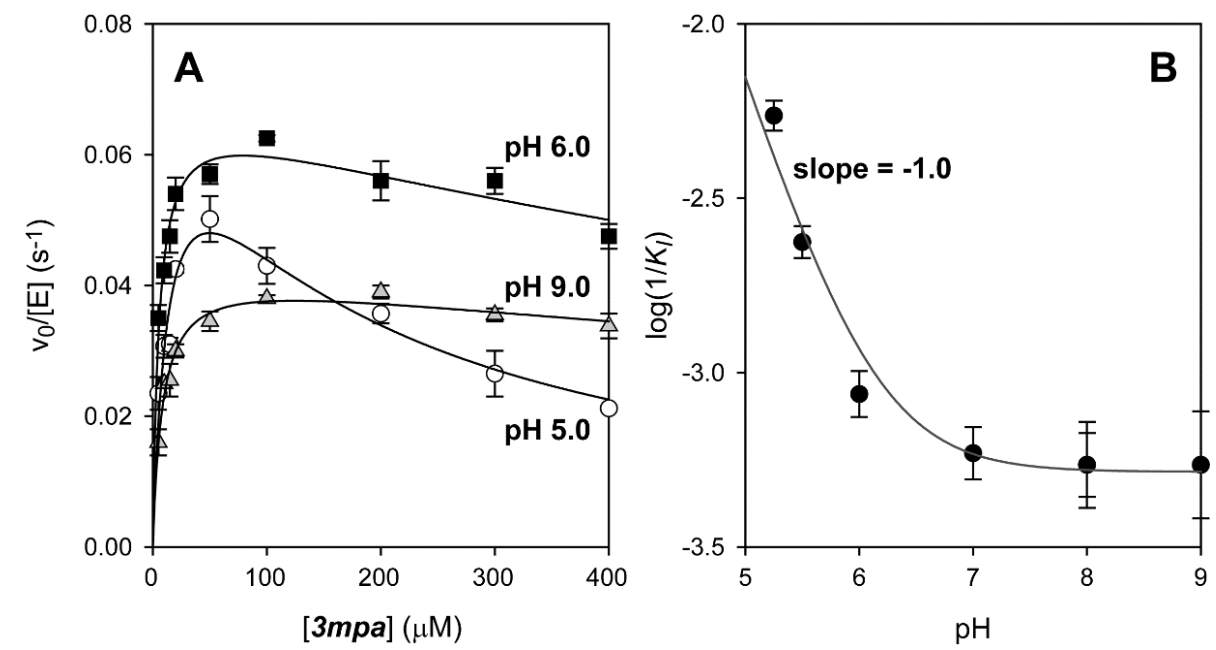

Figure S3. A. Steady-state kinetics of Y159F Av MDO catalyzed 3mpa reactions at different $\mathrm{pH}$ conditions. Within the acidic limb $(5.5<\mathrm{pH}<8.0)$, the initial rate of Y159F catalysis exhibits apparent substrate inhibitions and thus data were fit to equation $\mathbf{2}$ using non-linear regression to obtain kinetic parameters $\left(k_{c a t}, K_{M}\right.$, and $\left.K_{I}\right)$ as well as the error associated with these values. Under more basic conditions $(\mathrm{pH}>9)$, the data were better fit assuming standard Michaelis-Menten kinetics, and thus data were fit to equation $\mathbf{1}$ to obtain kinetic parameters. Table $\mathbf{S 2}$ summarizes the results obtained for the Y159F variant at selected $\mathrm{pH}$-values. B. Dixion-Webb plot $\left[\log \left(1 / K_{I}\right)\right.$ versus $\mathrm{pH}$ ] illustrating the $\mathrm{pH}$-dependent substrate inhibition of the Y159F Av MDO. 
Methods for interpreting $\mathrm{pH}$-dependent inhibition has been described previously by Dixon et al. ${ }^{8}$ For 3mpa-reactions, the concave down $\mathrm{pH}$-dependent substrate inhibition observed for the Y159F variant of $A v \mathrm{MDO}$ is diagnostic of an inhibitory protonation of the free enzyme or substrate. Given the pKa-values for 3mpa-carboxylate and thiol groups are 4.34 and 10.84, respectively ${ }^{9}$, it can be concluded that the observed ionization is associated with the free enzyme rather than the substrate. As the slope of the linear portion of the curve is unitary, it can be concluded that ionization of a single residue is responsible for this inhibitor effect. The pKa-value associated with this residue $(6.0 \pm 0.1)$ was obtained by fitting $\log \left(1 / \mathrm{K}_{\mathrm{I}}\right)\left(\right.$ or $\left.\mathrm{pK} \mathrm{K}_{\mathrm{I}}\right)$ as a function of $\mathrm{pH}$ data to equation (4) in Materials and Methods. While not entirely conclusive, this pKa-value is consistent with the protonation of a histidine residue. Given the importance of $\mathrm{H} 157$ in steady-state catalysis demonstrated here and previously ${ }^{1}$, it is reasonable to assume that protonation of $\mathrm{H} 157$ is responsible for the observed $\mathrm{pH}$-dependent inhibition of the Y159F variant.

Table S2. Steady-state kinetic parameters obtained for the Y159F Av MDO variant as a function of $p H$.

\begin{tabular}{|c|c|c|c|c|}
\hline $\mathrm{pH}$ & $k_{\text {cat }}\left(\mathrm{s}^{-1}\right)$ & $K_{M}(\mu \mathrm{M})$ & $K_{I}(\mu \mathrm{M})$ & $k_{\text {cat }} / K_{M}\left(\mathrm{M}^{-1} \mathrm{~s}^{-1}\right)$ \\
\hline 5.3 & $0.011 \pm 0.006$ & $4.6 \pm 1.5$ & $320 \pm 50$ & $23110 \pm 1010$ \\
\hline 5.5 & $0.068 \pm 0.002$ & $3.9 \pm 0.3$ & $570 \pm 40$ & $17500 \pm 600$ \\
\hline 5.5 & $0.072 \pm 0.002$ & $6.1 \pm 1.8$ & $420 \pm 120$ & $11830 \pm 3600$ \\
\hline 6.0 & $0.068 \pm 0.003$ & $5.4 \pm 1.0$ & $1150 \pm 220$ & $12600 \pm 2360$ \\
\hline 7.0 & $0.056 \pm 0.008$ & $7.7 \pm 2.8$ & $1700 \pm 620$ & $7350 \pm 2670$ \\
\hline 8.0 & $0.048 \pm 0.004$ & $7.3 \pm 1.6$ & $2020 \pm 540$ & $6580 \pm 1440$ \\
\hline 9.0 & $0.043 \pm 0.002$ & $8.4 \pm 1.2$ & $1840 \pm 400$ & $5100 \pm 800$ \\
\hline 10.0 & $0.030 \pm 0.003$ & $7.1 \pm 2.5$ & - & $4820 \pm 1280$ \\
\hline 10.0 & $0.030 \pm 0.003$ & $5.7 \pm 1.5$ & - & $4220 \pm 1550$ \\
\hline
\end{tabular}

- Substrate-inhibition is not observed at $\mathrm{pH}>9$, therefore the standard Michaelis-Menten equation was used to fit initial rate data.

\section{Calibration of pH under cryogenic conditions.}

The $\mathrm{pH}$ of a buffered solution can change dramatically under cryogenic conditions. ${ }^{10-12}$ Therefore, pKa-values determined in kinetic experiments performed at $37^{\circ} \mathrm{C}$ will be inconsistent with values obtained from spectroscopic measurements made in frozen solutions. However, the 'apparent $\mathrm{pH}$ ' can be determined by measuring the ionization of an appropriate indicator at both $37^{\circ} \mathrm{C}$ and under cryogenic conditions. For this purpose metmyoglobin $(\mathrm{Mb})$ was used as a $\mathrm{pH}$-indicator since the ferric iron spin-state change upon acid-alkaline $\mathrm{Mb}$ transition can be monitored independently by UV-visible $\left(37^{\circ} \mathrm{C}\right)$ and cryogenic EPR spectroscopy $(10 \mathrm{~K}) .{ }^{13-14}$

For these experiments, a $1.0 \mathrm{mM}$ stock solution of horse heart myoglobin (Mb) (Sigma-Aldrich, $\mathrm{p} / \mathrm{n}$ M1882) was prepared in dilute buffer solution. Aliquots of the stock solution were then diluted a second time using the same Good's buffer utilized for $\mathrm{pH}$-dependent activity measurements to obtain a final $\mathrm{Mb}$ concentration of $125 \mu \mathrm{M}$ at the desired $\mathrm{pH}$ value. Final buffer composition was $20 \mathrm{mM}$ Good's buffer and $50 \mathrm{mM} \mathrm{NaCl}$. UV-visible spectra were collected for $\mathrm{Mb}$ over a $\mathrm{pH}$ 
range of 5.5 to 10.5 ( $n=11$ points) at a fixed temperature of $37^{\circ} \mathrm{C}$. Following collection of UVvisible data at a selected $\mathrm{pH}$, a $250 \mu \mathrm{L}$ aliquot of the Mb solution was transferred into an EPR tube using a Hamilton gas-tight syringe equipped with a 6-inch needle. Samples were frozen by immersion of the EPR tube into a batch of liquid $\mathrm{N}_{2}$ cooled acetone. Freezing samples in this fashion allows for rapid freezing $(\sim 2 \mathrm{sec})$ and uniformity in the freezing rate for each sample. Xband EPR of cryogenic samples $(10 \mathrm{~K})$ was performed for each sample.

The pKa-value $(8.92 \pm 0.1)$ for this transition was measured spectrophotometrically at $37{ }^{\circ} \mathrm{C}$ by following the change in absorbance at 544 and $581 \mathrm{~nm}$. This value agrees well the published value of $\mathrm{Mb}$ at this temperature. ${ }^{13-14}$ These same UV-visible samples were then transferred into EPR tubes, frozen in liquid $\mathrm{N}_{2}$ and the distribution of high-spin $(S=5 / 2)$ acid-Mb and low-spin $(S=$ 1/2) alkaline-Mb was determined by EPR. Under cryogenic conditions, the apparent pKa for acidalkaline $\mathrm{Mb}$ is $8.51 \pm 0.2$, indicating that the apparent $\mathrm{pH}$ under cryogenic conditions is $+0.41 \mathrm{pH}$ units more basic relative to measurements made at $37^{\circ} \mathrm{C}$.

Figure S4. Use of myoglobin to calibrate apparent $p H$ for ambient solution and frozen cryogenic conditions.
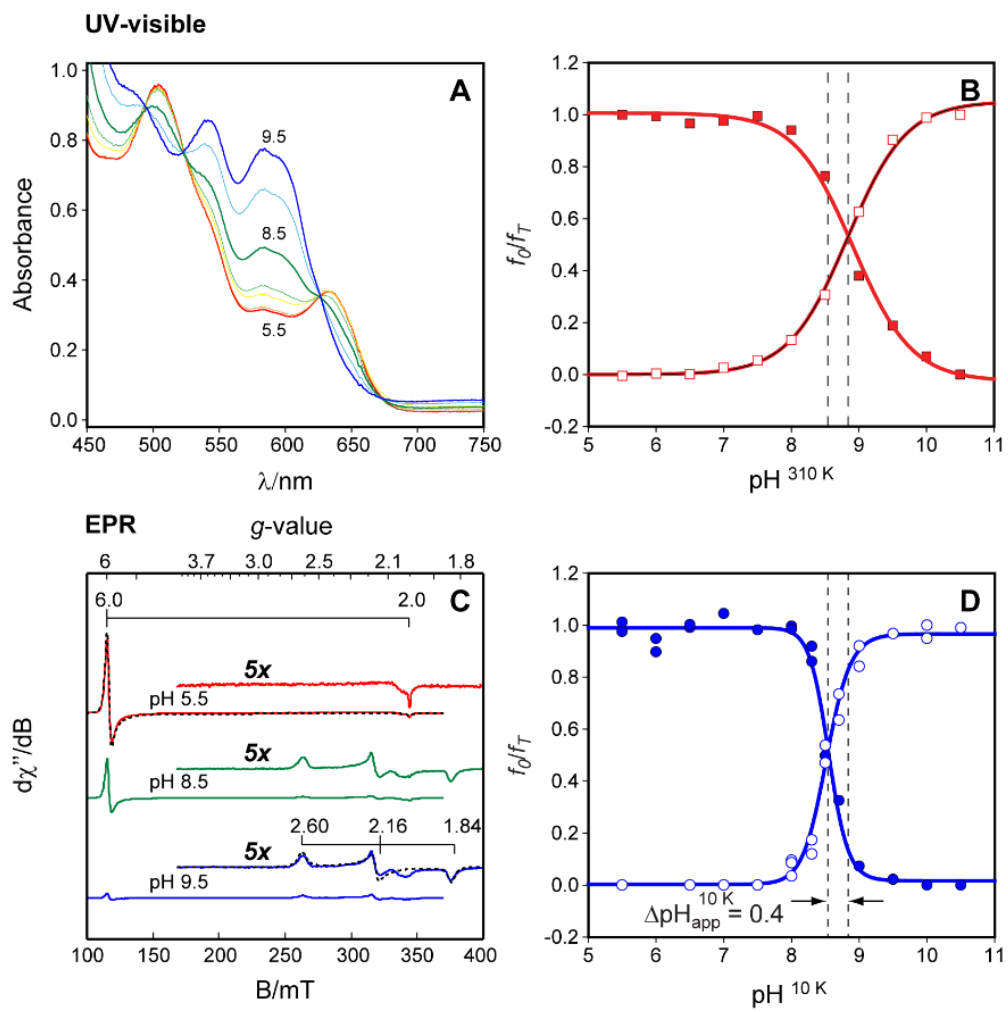

Figure S4. Change in UV-visible spectra of myoglobin (Mb) measured at $310 \mathrm{~K}(\mathbf{A})$ as compared to $\mathrm{pH}$ dependent EPR spectra $(\mathbf{C})$ collected at $10 \mathrm{~K}$. The fraction $\left(f_{0}\right)$ of high-spin aquaMb (solid square/circle) and low-spin alkalineMb (open square/circle) observed by UV-visible (B) and EPR (D) was normalized for the total amount of myoglobin in solution $\left(f_{T}\right)$ and plotted versus $\mathrm{pH}$. The resulting data was fit to equation (4) to obtain the pKa-value for aquaMb at 310 and $10 \mathrm{~K}$. 
Figure S5. Formation of the cys-bound Av ES-NO $(S=1 / 2)$ signal with increasing $p H$.

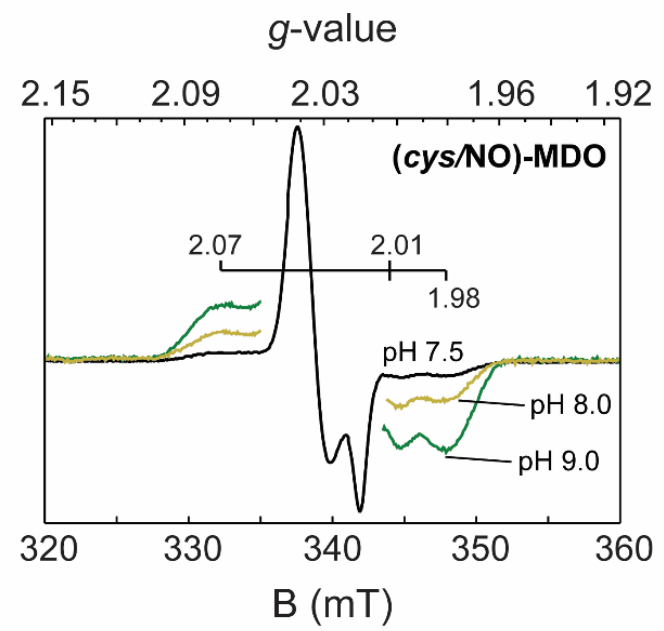

Figure S5. $10 \mathrm{~K}$ EPR spectra of cys-bound $A v$ ES-NO as a function of $\mathrm{pH}$. For clarity, the dinitrosyl iron species with g-values $(2.040,2.036$, and 2.015) was subtracted from all but the signal obtained for samples prepared at $\mathrm{pH}$ 7.5. Simulation parameters for the wild-type $A v$ ESNO produced in wild-type enzyme at $\mathrm{pH} 7.5$ are reported in Table 4. For simplicity, the $\mathrm{pH}$ values indicated refer to the $\mathrm{pH}$ at which the sample was prepared at ambient temperature. The apparent $\mathrm{pH}\left(\mathrm{pH}_{\mathrm{app}}\right)$ at cryogenic temperature $(10 \mathrm{~K})$ is obtained by adding $0.41 \mathrm{pH}$ units to this value.

Figure S6. Mössbauer spectra of Av MDO free enzyme and 3mpa-bound H157N and Y159F variants at $\mathrm{pH} 8.0$ and 9.0.

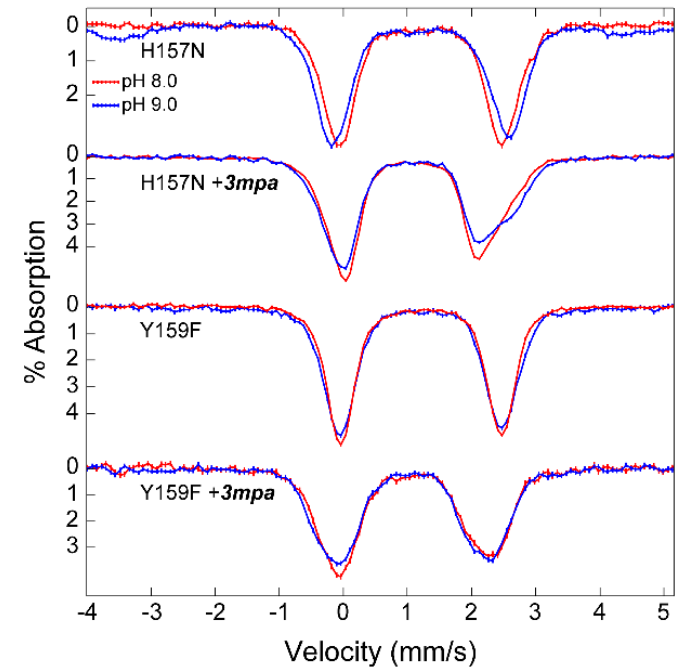

Figure S6. ${ }^{57} \mathrm{Fe}$-enriched Mössbauer spectra of reduced variants $\mathrm{H} 157$ and Y159F (as indicated on figure) in the absence or presence of 3mpa, and in HEPES pH 8.0 (red) or CHES pH 9.0 (blue). The spectra are all presented with equal areas to highlight $\mathrm{pH}$ dependent changes. With the exception of resting Y159F, all spectra can be fit with two doublets having linewidths, $\Gamma \sim 0.4$ $\mathrm{mm} / \mathrm{s}$. 


\section{ADV docking studies on 3mpa-bound Pa3MDO.}

A bidentate model for 3mpa Fe-coordination via thiol and carboxylate functional groups within the MDO active site was recently proposed by Jameson and Karplus et al. ${ }^{15}$ This was presented as an alternative to the 'thiolate-only' Fe-coordination described here and elsewhere. ${ }^{1-2}$ While no experiments were performed in this report to verify bidentate 3mpa Fe-coordination, their model nicely illustrates how differences in the positioning of a catalytically important Arg residue within a thiol dioxygenase active site influences substrate-specificity.

The structural model for the bidentate 3mpa Fe-bound MDO was generated by substrate docking within an edited Pa3MDO active site (pdb code 4TLF) using the software AutoDock Vina (ADV). While this method has been previously used to estimate ligand binding interactions in metalloenzymes, to our knowledge, these studies are limited to systems with coordinatively saturated alkali $\left(\mathrm{Ca}, \mathrm{Mg}\right.$ ) or $\mathrm{Zn}$ metal cations. ${ }^{16-19}$ These metals have a closed valence electron shell and thus lack significant ligand field contributions associated with unpaired $d$-electrons. Calculations involving the direct binding of ligand at a transition metal typically require a higher level of computational theory than provided by ADV. ${ }^{20}$ Further, metal coordinated solvent waters are not generally deleted from the initially posed structures. ${ }^{21}$

A more significant limitation to the accuracy of this model comes from the heavily edited initial 'posed' structure for the starting point for ADV calculations. This structure was produced by manually deleting (3) solvent waters from the XRD Fe-site. This is half of the Fe-bound ligands along an entire octahedral face. Further, as noted in their publication ${ }^{15}$, ADV does not handle iron or sulfur well, and thus the $\mathbf{3 m p a}$-thiolate was manually coordinated to the iron trans to H91 to replace the deleted solvent water [Fig. 1B, solvent (1)]. Active site water molecules are critical for establishing an accurate binding surface by any computational method as they have a large dielectric constant. ${ }^{22-23}$ Therefore, arbitrarily removing all Fe-bound solvents significantly influences the strength of active site electrostatic and hydrogen bonding interactions resulting in biased scores for computed structures. ${ }^{18,21}$ It therefore comes as no surprise the resulting ADV predicted structure reflects direct coordination of the $3 m p a$-carboxylate anion to an unshielded iron(II) divalent cation. In our view, the use of this extensively edited starting structure places a significant 'thumb on the scale' with respect to scoring of ADV computed structures; effectively forcing a bidentate 3 mpa Fe-coordination.

Having said this, the proposed intermolecular interactions between the $\mathbf{3 m p a}$-carboxylate, cationic $\mathrm{R} 168$, and $\mathrm{Fe}(\mathrm{II})$ are all very reasonable and likely play an important role in substrate-coordination within the MDO active site. However, while not explicitly stated in their manuscript, the bidentate model for 3mpa Fe-coordination (presented in their Figure 1) implies 'atomic level' resolution as selected active site distances are reported to within a tenth of an angstrom. ${ }^{15}$ In light of the heavily edited starting pose, and lower computational theory applied, there is simply insufficient computational resolution to distinguish 3mpa-binding modes (if any) at the Fe-site. Further, their bidentate model is inconsistent with experimental conclusions taken from kinetic and EPR spectroscopic studies performed on $A v$ MDO with multiple thiol-bearing substrates (3mpa, cys, $\boldsymbol{c a}$, and $\boldsymbol{e t}) .{ }^{1-2}$ Consequently, we view their bidentate model for $\mathbf{3 m p a} \mathrm{Fe}$-coordination with considerable skepticism. 


\section{REFERENCES.}

1. Crowell, J. K.; Sardar, S.; Hossain, M. S.; Foss Jr, F. W.; Pierce, B. S., Non-chemical proton-dependent steps prior to O2-activation limit Azotobacter vinelandii 3-mercaptopropionic acid dioxygenase (MDO) catalysis. Arch Biochem Biophys. 2016, 604, 86-94.

2. $\quad$ Pierce, B. S.; Subedi, B. P.; Sardar, S.; Crowell, J. K., The "Gln-Type” Thiol Dioxygenase from Azotobacter vinelandii Is a 3-Mercaptopropionic Acid Dioxygenase. Biochemistry 2015, 54 (51), 7477-7490.

3. Crowell, J. K.; Li, W.; Pierce, B. S., Oxidative uncoupling in cysteine dioxygenase is gated by a proton-sensitive intermediate. Biochemistry 2014, 53 (48), 7541-8.

4. Smitherman, C.; Gadda, G., Evidence for a Transient Peroxynitro Acid in the Reaction Catalyzed by Nitronate Monooxygenase with Propionate 3-Nitronate. Biochemistry 2013, 52 (15), 2694-2704.

5. Li, W.; Pierce, B. S., Steady-state substrate specificity and $\mathrm{O}_{2}$-coupling efficiency of mouse cysteine dioxygenase. Arch Biochem Biophys. 2015, 565, 49-56.

6. Pierce, B. S.; Gardner, J. D.; Bailey, L. J.; Brunold, T. C.; Fox, B. G., Characterization of the nitrosyl adduct of substrate-bound mouse cysteine dioxygenase by electron paramagnetic resonance: electronic structure of the active site and mechanistic implications. Biochemistry 2007, 46 (29), 8569-78.

7. Li, W.; Blaesi, E. J.; Pecore, M. D.; Crowell, J. K.; Pierce, B. S., Second-sphere interactions between the $\mathrm{C} 93-\mathrm{Y} 157$ cross-link and the substrate-bound $\mathrm{Fe}$ site influence the $\mathrm{O}_{2}$ coupling efficiency in mouse cysteine dioxygenase. Biochemistry 2013, 52 (51), 9104-19.

8. Dixon, M.; Webb, E. C., Enzymes. Academic Press: New York, 1979.

9. Forlano, P.; Olabe, J. A.; Magallanes, J. F.; Blesa, M. A., The mechanism of oxidation of 3-mercaptopropionic acid. Can J Chem. 1997, 75 (1), 9-13.

10. Sieracki, N. A.; Hwang, H. J.; Lee, M. K.; Garner, D. K.; Lu, Y., A temperature independent $\mathrm{pH}$ (TIP) buffer for biomedical biophysical applications at low temperatures. Chem Commun (Camb) 2008, (7), 823-825.

11. Orii, Y.; Morita, M., Measurement of the $\mathrm{pH}$ of Frozen Buffer Solutions by Using $\mathrm{pH}$ Indicators. J Biochem. 1977, 81 (1), 163-168.

12. Williams-Smith, D. L.; Bray, R. C.; Barber, M. J.; Tsopanakis, A. D.; Vincent, S. P., Changes in apparent $\mathrm{pH}$ on freezing aqueous buffer solutions and their relevance to biochemical electron-paramagnetic-resonance spectroscopy. Biochem J 1977, 167 (3), 593-600.

13. George, P.; Hanania, G., The ionization of acidic metmyoglobin. Biochemi J 1952, 52 (3), 517-523.

14. Svistunenko, D. A.; Sharpe, M. A.; Nicholls, P.; Blenkinsop, C.; Davies, N. A.; Dunne, J.; Wilson, M. T.; Cooper, C. E., The pH dependence of naturally occurring low-spin forms of methaemoglobin and metmyoglobin: an EPR study. Biochem J 2000, 351 (Pt 3), 595-605.

15. Aloi, S.; Davies, C. G.; Karplus, P. A.; Wilbanks, S. M.; Jameson, G. N. L., Substrate Specificity in Thiol Dioxygenases. Biochemistry 2019, 58 (19), 2398-2407.

16. Adeniyi, A. A.; Ajibade, P. A., Comparing the Suitability of Autodock, Gold and Glide for the Docking and Predicting the Possible Targets of Ru(II)-Based Complexes as Anticancer Agents. Molecules 2013, 18 (4), 3760-3778.

17. Pottel, J.; Therrien, E.; Gleason, J. L.; Moitessier, N., Docking Ligands into Flexible and Solvated Macromolecules. 6. Development and Application to the Docking of HDACs and other Zinc Metalloenzymes Inhibitors. J Chem Inf Model. 2014, 54 (1), 254-265. 
18. Kitchen, D. B.; Decornez, H.; Furr, J. R.; Bajorath, J., Docking and scoring in virtual screening for drug discovery: methods and applications. Nat Rev Drug Discov. 2004, 3 (11), 935 949.

19. Seebeck, B.; Reulecke, I.; Kämper, A.; Rarey, M., Modeling of metal interaction geometries for protein-ligand docking. Proteins 2008, 71 (3), 1237-1254.

20. Nechay, M. R.; Valdez, C. E.; Alexandrova, A. N., Computational Treatment of Metalloproteins. J Phys Chem B 2015, 119 (19), 5945-5956.

21. Poornima, C. S.; Dean, P. M., Hydration in drug design. 1. Multiple hydrogen-bonding features of water molecules in mediating protein-ligand interactions. J Comput Aided Mol Des 1995, 9 (6), 500-512.

22. Hetényi, C.; van der Spoel, D., Efficient docking of peptides to proteins without prior knowledge of the binding site. Protein Sci. 2002, 11 (7), 1729-1737.

23. Forli, S.; Huey, R.; Pique, M. E.; Sanner, M. F.; Goodsell, D. S.; Olson, A. J., Computational protein-ligand docking and virtual drug screening with the AutoDock suite. Nat. Protoc. 2016, 11, 905. 